\section{Antroposen Çağı'nda pandemi ve kentlerin durumu}

\author{
Erkan Polat ${ }^{\top} \odot$, Sümeyye Kahraman ${ }^{2 *}$
}

'Prof. Dr. | Süleyman Demirel Üniversitesi, Mimarlık Fakültesi, Şehir ve Bölge Planlama Bölümü, Isparta - Türkiye ${ }^{2}$ Doktora öğrencsi | Süleyman Demirel Üniversitesi, Şehir ve Bölge Planlama Bölümü, Isparta - Türkiye
* Sorumlu Yazar / Corresponding Author: Sümeyye Kahraman Süleyman Demirel Üniversitesi Mimarlık Fakültesi Şehir ve Bölge Planlama Bölümü 32260 Çünür, Isparta/Türkiye

E-posta: sumeyyekahraman1994@gmail.com

Alındı/Received: 14 Ekim / October 2020 Düzeltildi/Revised: 8 Mart / March 2021 Kabul/Accepted: 8 Mart / March 2021 Erken Görünüm/Early View: 19 Mart / March 2021 Yayımlandı/Published: 28 Haziran 2021

\section{Öz}

İnsanlar, 4,5 milyar yaşında olan Dünya üzerinde yaklaşık 200.000 yıldır yaşamaktadır. İnsanlık ilk günden beri gezegenin tüm organizmalarının bağlı olduğu fiziksel, kimyasal ve biyolojik sistemleri temelden değiştirmeye başlamış, özellikle son 60 yılda, bu etkiler eşi görülmemiş bir oranda ve ölçekte, özellikle kentlerde kendini göstermiştir. Geçmişteki salgınlar ve 2019 yılında ortaya çıkan COVID-19 salgını tesadüfen yaşanmamıştır. Salgının bir insan yaratımı olduğunu anlamak önemlidir; çünkü bu problemi, bulunduğumuz tür ve yarattı̆̆ımız gezegen (kentler) yüzünden ortaya çıkardık. Geçmiş ve mevcut pandemiler, Antroposen olarak bilinen insan yapımı gezegen krizinin sadece bir yönüdür; iklim değişikliği, biyolojik çeşitlilik kaybı ve diğer sorunların hepsi birbirine bağlıdır. Bu sorunların temel taşlarından biri Antroposen'in bir parçası olan kentlerdir ve bu sorunların etkileri en çok kentlerde yoğunlaşmaktadır. 2020-2021 yıllarının küresel sorunu olan pandemi gibi... Bu çalısmada Antroposen Çağı'nın bir sorunu olan pandemilerin kentteki geçmişi-geleceği, Antroposen Çă̆ı'’nın başlamasına neden olan felaket mekânları olan, asıl sorunları (insanlar) içinde barındıran kentler ile bağlantısı kuramsal bir tartışma bazında ele alınmıştır. Kentli insanlar yüzünden giderek artan COVID-19 salginı üzerinden kentsel alanlarda planlamayla getirilecek çözüm yöntemlerine ilişkin öneriler çalışmada sunulmuştur.

Anahtar sözcükler: Antroposen çağı, pandemi, kent, COVID-19

\section{Giriş}

Gezegendeki insan varlı̆̆, ancak insanlarm yokluğundan sonra okunabilir olacak.

\section{-Claire Colebrook}

Çağdaş kentleşme oran, ölçek, konum ve biçim bakımından geçmişten oldukça farklılık göstermektedir (Seto vd., 2010). Dünya nüfusunun yaklaşık 1 milyar kişiyi yaşattığı 1800 yılında, 1 milyondan fazla nüfusu olan tek kent Pekin'di. 1900'e gelindiğinde, yaklaşık 16 kent bu barajı aşmıștı; bu rakam binyılın başında 200'e
Pandemic in the Anthropocene epoch and the status of

\section{cities}

\section{Abstract}

Humans have been living on Earth, which is 4.5 billion years old, for approximately 200,000 years. Since the first day of its existence, bumanity has begun to fundamentally change the physical, chemical and biological systems that depend on all the organisms of the planet, especially in the last 60 years, these effects have manifested themselves at an unprecedented rate and scale, especially in cities. The past pandemics and the COVID-19 pandemic that occurred in 2019 were not accidentally experienced. It is important to understand that the pandemic is a man-made; because we created this problem because of the species we are in and the planet (cities) we created. Past and present pandemics are just one aspect of the man-made planetary crisis known as the Antbropocene; climate change, biodiversity loss and other problems are all interdependent. One of the cornerstones of these problems are the cities that are a part of the Anthropocene and the effects of these problems are mostly concentrated in cities. Like the pandemic, which is a global problem of 2020-2021... In this study, the past and future of pandemics, which are a problem of the Anthropocene epoch, in the city, the disaster areas that caused the start of the Anthropocene epoch. The connection with the cities hosting the main problems (bumans) is discussed in the context of a theoretical discussion. Suggestions regarding the solution methods to be brought by planning in urban areas dealing with the COVID-19 epidemic, which is increasing due to urban people, are presented in the study.

Key words: Anthropocene epoch, pandemic, city, COVID-19

yükselmişti. Eğer eğilim böyle devam ederse, 2025 yilında dünya genelinde bir milyondan fazla nüfuslu yaklaşık 600 kent olacaktır.

İnsan faaliyetleri bugün karaların dörtte üçünü ve suların üçte ikisini önemli ölçüde değiştirmiş, gezegeni yeni bir dönemin doğuşuna itmiştir. Bugün, kentsel alanlar küresel toprak yüzeyinin sadece $\% 2$ 'sini oluştursa da (Akbari vd., 2009), dünya nüfusunun yarısından fazlası kentlerde yaşamakta ve sekiz kentliden biri 10 milyondan fazla nüfusa sahip 50 "mega kent" ten birinde yaşamaktadır. Bir yandan meta-kentleşme gibi 
küreselleşmiş sosyo-uzamsal süreçlerin ortaya çıkmasına tanık olunmaktayken öte yandan düzensiz bir sosyomekânsal gelişme ölçeği izlenmektedir.

Kent, dünyanın ve insanlığın olası geleceğinin aynı anda hem organize edildiği hem de çatıştı̆̆1 genelleştirilmiş, gezegensel bir durum haline gelmişken, kentleşme yaşam kalitesini tehdit eden zorluklar yaratırken ve 21. yüzyılın en acil çözülmesi gereken sorunlarından biri haline gelmişken (Parnell, 2016), aynı zamanda bu zorlukları çözme umudunu da temsil eder ve geleceğe dair olası çözümler için gereken ortamı da sağlar.

İnsan faaliyetleri, artik gezegenin tarihindeki bu zamanın yani "Antroposen" olarak adlandirılan bir dönemin sahip olacağ1 ölçüde dönüştürülmesinde biyo-fiziksel itici güçlerle rekabet ediyor, hatta aşıyor. Bu durum, insanın dünyasını anlamlandırma ve ölçeklendirmedeki bir tür kesintiyle başa çıkma girişiminin yeni bir versiyonudur; Antroposen, gezegenin geleceğine uzak "biyo-coğrafik bir insan arşivi” dir.

Antroposen, insanların gezegen ölçeğinde -doğa gibi- jeofiziksel ve jeotarihsel bir güç haline geldiği, çok sayıda aşılmaz sınırı geçtiği ve bunu bir bütün olarak Dünya sisteminin işleyişini etkilediği söylenen, gezegen tarihindeki jeolojik bir döneme işaret etmektedir. Antroposenin oldukça hızlı kullanılan bir birim haline gelmesine rağmen, Antroposen figürü ve söyleminin neden hem bir nedensel güç hem de bir endișe konusu olarak yorumlandığ1 ve ardından ele aldığı kolektif konunun kim ve ne olduğu hala net değildir (Chakrabarty, 2009; Crist, 2013).

1972'deki Roma kulübünün ünlü Meadows Raporu'nun (Büyümenin Sinırları) kehanetleri ve daha fazlası bir bir gerçekleşmiştir: İklim değişikliği, küresel 1sınma, ekonomik ve çevresel krizler, salginlar, biyolojik çeşitlilik ve tür kaybı, deniz seviyesinin yükselmesi, toksinlerin biyolojik birikimi kitlesel göçler ve zorla yerinden edilmeler, mülteci krizleri, kent savaşları, yeni çatışmalar, kentsel bilgi üretiminin tehlikeleri ve üssel olarak artan insan nüfusu...

Birleşmiş Milletler de yaklaşan küresel krize işaret ederek 2030 Sürdürülebilir Kalkınma Ajandasi'n1 yayımlamıştır: İnsan baskısı çevresel y1kıma, iklim değişikliğine, toplumsal eşitsizliğe ve diğer negatif küresel sonuçlara yol açmıştır. Bu çevresel krizler ortaya çıkan bulaşıcı hastalıklar yoluyla doğrudan insan sağlığını etkiler hale gelmiştir. Ebola, grip, SARS, MERS ve koronavirus (2019-nCoV) gibi, yüksek ölüm ve hastalık oranlarıyla, ticaret ve ulaşım ağlarını bitirmesiyle ve toplumsal huzursuzluk yaratmasiyla (Pike vd., 2014) tüm yaşamı etkiler hale gelmiştir.

Kentler bugüne değin eşi görülmemiş bir hızla ve ciddiyetle ortaya ç1kan COVID-19 salg1nı gibi bir durumla hiçbir zaman sınanmadı. Bu krizin kentler ve insanları üzerinde fiziksel, ekonomik ve sosyal açıdan nesiller boyu yankılanacak bir iz birakacağ1 kesin görünmektedir.

\section{Antroposen}

Antroposen farklıdır. Bu, Dünya’nın Güneş’in etrafinda dolaştığını kavrayan Copernicus gibi bir bilimsel gerçekleştirmenin, insanların bilimin ötesindeki şeylerle ilgili görüşlerini temelden değiştirebileceği anlardan biridir. Bu, bazı ders kitaplarını yeniden yazmaktan daha fazlası demektir. İnsanlar ve dünyası arasındaki ilişkiden korktuğunu düşünmek ve buna göre davranmak demektir. (The Economist, 2011)

Antroposen'in etimolojik kökeni Yunanca iki kelimenin birleşimidir: "İnsan (buman)" anlamina gelen anthropos ve "yeni (new)" anlamina gelen kainos. Eklendiği köke "son döneme ait (recent)" anlamı katan -cene son eki ile son şeklini alır (Peters, 2012, s. 265). Kökenlerine bakıldığında Antroposen kısaca "yeni insan çağ1" olarak ya da Rafferty’e (2020) göre "son insan çağ1 (recent age of man)" olarak nitelendirilebilir.

"Antroposen" terimi, 1980'lerin başında ABD'li biyolog Eugene F. Stoermer tarafından türetilmiş ve 1995 y1lında ozon tüketen bileşiklerin etkilerini keşfettiği için Nobel Ödülü alan Paul J. Crutzen tarafından bilimsel bir konferansta genel kullanıma dâhil edilmiştir. İnsanın Dünya üzerindeki etkisi ile karakterize edilen jeolojik zaman ölçeğini 1873'te "Antropozoik" adiyla öneren de İtalyan jeolog Antonio Stoppani'dir (Crutzen, 2002, s. 23). Stoermer ve Crutzen 2000 yilinda yayınlanan makalelerinde Antroposen Çağı'nı resmi bir terminoloji olarak kullanmış ve kamuoyunun dikkatini çekmiştir. Terimin önceki kullanımları sayıca çok görünse de ya rastgele ve bağlam dışı kullanılmış ya da yeterli bilimsel kanıt ve net açıklamalar ile desteklenmediklerinden dolayı gerekli ilgi oluşmamıştır (bkz. Aykanat, 2017, s. 2).

2008'de İngiliz jeolog Jan Zalasiewicz ve meslektaşları resmi bir jeolojik aralık olarak Antroposen Çağı'nı benimsemeye yönelik ilk teklifi ortaya koymuş ve ardından resmileștirmek için çalıșmalar yapmıştır. Buna göre son zamanlarda Dünya'nın Holosen'den Antroposen Çağı'na geçtiği, insanların küresel çevre üzerindeki etkilerinin, özellikle Sanayi Devrimi’nden bu yana, Dünya yüzeyinde belirgin değişikliklere yol açtı̆̆1, bunların son stratigrafik kayıtlara yansıtılabileceği, bunun da Antroposen Çağı'nın başlamasına neden olabileceği öne sürülmüştür (Zalasiewicz vd., 2008). 
Antroposen Çalışma Grubu (AÇG), Antroposen kavramını stratigrafik olarak analiz etmiş ve stratal özelliklere açıça yansiyan jeolojik süreçlerin belirgin bir değişikliğini temsil ettiğini, bu değişikliklerin önerilen Antroposenin yeni bir jeolojik zaman birimi oluşturmak için Holosen'den yeterince farklı olduğunu gösterdiğini belirtmiştir (Zalasiewicz vd., 2017, s. 59).

Antroposen Çağı ortaya atıldıktan sonra kavram, insan faaliyetinin Sanayi Devrimi'nden itibaren dünyadaki çevresel sistemleri değiştiren (Rafferty, 2020) büyük bir "itici faktör" olduğu (Certini ve Scalenghe, 2011, s. 1272) bir jeolojik çağ için kullanılmış (Hamilton, 2014), bunun yanı sıra kimyasal ve klimatolojik güçlerin yerini alan baskın bir güç haline geldiğini gösteren yeni bir dönem olarak da tanımlanmıştır (Hine, 2019).

Crutzen ve Steffen (2003), Antroposenle Sanayi Devrimi'nin başlangıcı olan 18. yüzyılın sonlarında belirgin bir değişimin hissedildiğini savunmaktadır. Buharlı makinelerin icadiyla gezegen için en fazla olumsuz etkinin endüstriyel bileşenlerin yarattığ1 büyük reaksiyonla başlamış, kentsel alanların ve kentsel nüfusun hızla büyümeye başlaması ve çevre sorunlarını beraberinde getirmesi bunu izlemiştir. Yirminci yüzyll ise insanlar ve yaşam destek sistemleri arasındaki ilişkide önemli bir değişim noktası olmuştur. 1945'teki atom bombası olayının ardından insan tarafindan üretilen ilk radyoaktif parçacıklar jeolojik kayıtlarda yer almış ve insan faaliyetleri küreyi etkileyen egemenliğini iyice hissettirmeye başlamıştır (Crutzen ve Steffen, 2003). Savaş sonrası dönem insan nüfusunda üssel büyüme, fosil yakıt kullanımı, su kullanımı, gıda üretimi, uluslararası iletişim ve arazi kullanımında hızlı bir dönüşümü de beraberinde getirmiştir (Demos, 2017; Rafferty, 2020).

\section{Kentler ve Pandemi}

Bugün epidemiyolojik bir geçişe tanık olunmaktadır (Cicolella, 2013); Dünya Sağllk Örgütü, sağl1k sorununu bir kez daha ön plana çıkaran ve çevrenin ve onun bozulmasinın sorumluluğunu sorgulayan "kronik hastalıkların küresel salgını"ndan bahsetmektedir. Bu yeni sağlık sorunu ve krizi karşısında kentsel planlama, kendi sorumluluğuna ve ilgisizliğine bir kez daha meydan okumaktadır. 2017 y1lında, kardiyovasküler hastalıklar (ölümlerin \%40’1) bulaşıcı hastalıkların çok ötesindeyken, ikinci neden kanserdi (ölümlerin \%27'si). Günümüzdeki küresel ölçekteki kronik hastalık patlaması ile ilgili sorunlar ise geçmişin bulaşıcı hastalıklarıyla aşağ1 yukarı benzerdir. XIX. ve XX. yüzyllın başlarında bulaşıcı hastalık salgınlarının sosyal ve kentsel nedenleri ve güçsüz bir tıp karşısında, sağlık sorunlarına mekânsal çözümler getirmek için hijyenist/sağlıklı kent planlaması oluşturuldu.

Bugün, kenti zamanın kent planlaması öğretilerine paralel olarak sadece sağlık boyutuna indirgeyen hijyenist kent planlaması hatasından da kaçınmak gerekir. Kent planlamasının karmaşıklığını ve işleyişi ile bağlantılı sosyal, ekonomik, çevresel ve politik sorunları unutmadan, oluşan bu yeni kent sorununu ve kent sağlığ1 (ekosistem sağllı̆̆1 ve insan sağllğı) üzerindeki etkisini bütünleştirmek gerekir.

M. Foucault (1977) tarihte salginlarla mücadele etmede tedavi amaçlı olmayan iki ana mekânsal kontrol tekniğinden bahseder: Dişlama (cüzzamda olduğu gibi bölgeden dışlama, hastanın sınır dışı edilmesi, tehlikeli bedenleri toplumdan çıkarma) ve gözetim/ karantina (vebada olduğu gibi bölgenin karantinas1, s1hhi kordon, hapsetme, dezenfeksiyon, izolasyon). $\mathrm{Bu}$ hijyenik mekânsal bulaşma kontrol teknikleri bu nedenle, bilinmeyen bir sağlık tehdidine tıbbi bir yanıt bulunmadığında uygulanır. Böylece, kent planlamasının doğuşuna katkıda bulunacak olan XIX. ve XX. yüzyılın başlarındaki büyük hijyenist mekânsal müdahaleleri de ön plana çıkmıştır.

$\mathrm{Bu}$ yüzyıllarda, kentlerde korkutucu aşırı ölüm oranları vard1; ortalama $\% 36.1$ ve yaşam beklentisi 25 yıldı. Kentteki yaşam koşulları, sağlıksız barınma, kalabalıklık, yoğunluk, kir, pis koku, insan ve hayvanın karışması bu aşırı ölüm ve tekrarlanan bulaşıcı salgınlardan sorumlu kabul edildi. Hipokrat düşüncesine göre çevre suçluydu, doğrudan kötü iklim ve topografik koşullar, sağlıksız konutlar ve sağliksız yerel çevre suçluydu. Pasteurian devrim Sanayi Devrimi'nin sorunlarına cevap arıyordu.

Avrupa'da, CIAM (Uluslararası Modern Mimarlik Kongresi) (1928-1956) ve Bauhaus (1919-1933) modern hareketi yansitırken 1933 yllinda, CIAM'in doktrinel bir manifestosu olan Atina Şartı, hijyenik bir kent kavramını savundu. 1970'lerde patlak veren ekolojik ve çevresel krizin ivme kazanması ve gündem 21 ile 1992'de Rio'dan başlayarak birkaç Dünya Zirvesi düzenlenmesi ile yeni ortaya çıan sürdürülebilir kalkınma zorunluluğu (1987), Atina karşıtı bir Şart olan Avrupa Sürdürülebilir Şehir Şartı Aalborg Şartı (1994) ile kent planlamasına yansittlacaktır.

İnsanlar doğal çevrelerini dönüştürdü, zarar verdi, bozdu, yok etti. Bunları yaparken ekosistem içerisinde birlikte bulundukları canlı/cansız varlıklar1 etkiledi, onların bu faaliyetleri patojenleri ortaya çıkararak insan-hayvan-çevre arayüzünün karışmasına sebep oldu (Hassell vd., 2017). COVID-19 virüsü de Ebola, AIDS, SARS, kuş gribi ve domuz gribi hastalıkların çıkması ile benzerlik göstermektedir; hepsi hayvanlardan kaynaklıdır ve insanlığın doğayı aşırı sömürüsünün etkisiyle insanhayvan-çevre arayüzünden doğan zoonotik ve diğer hastalıkların yayılmasının arkasındaki faktörlerden biri olduğuna dair kanıt niteliği olmuştur (WWF, 2020, s. 3).

Antroposen Çağı'nın ilk işaretleri olarak insanlar dünyaya yayıldıkça çevreyi değiştirmiş/dönüştürmüş bulaşıcı hastalıkların da ortaya çıkmasına/yayılmasına 
Tablo 1. Önemli pandemi ve salgınlar (LePan, 2021'den uyarlanmıștır)

\begin{tabular}{|c|c|c|c|}
\hline Hastalık adı & Zaman dilimi & Hastalığa neden olan tür & Yaklaş1k ölüm (kişi) \\
\hline Antonine Veba & $165-180$ & Çiçek hastalığı veya kızamık olduğuna inanılıyor & 5 milyon \\
\hline Japon Çiçek Hastalığ1 Salgını & $735-737$ & Variola major virüsü & 1 milyon \\
\hline Justinian Veba & $541-542$ & Yersinia pestis bakterisi / Siçanlar, pire & 30-50 milyon \\
\hline Kara Ölüm & $1347-1351$ & Yersinia pestis bakterisi / Siçanlar, pire & 200 milyon \\
\hline $\begin{array}{c}\text { Yeni Dünya Çiçek Hastalığı } \\
\text { Salginı }\end{array}$ & 1520 - sonras 1 & Variola major virüsü & 56 milyon \\
\hline Londra Büyük Veba & 1665 & Yersinia pestis bakterisi / Sıçanlar, pire & $100 \mathrm{bin}$ \\
\hline İtalyan Vebas 1 & $1629-1631$ & Yersinia pestis bakterisi / Siçanlar, pire & 1 milyon \\
\hline Kolera Salginlar1 1-6 & $1817-1923$ & V. cholerae bakterileri & $>1$ milyon \\
\hline Üçüncü Veba & 1885 & Yersinia pestis bakterisi / Sıçanlar, pire & 12 milyon (Çin, Hindistan) \\
\hline Sarıhumma & $1800^{\prime}$ lerin sonu & Virüs / Sivrisinekler & 100 bin -150 bin (ABD) \\
\hline Rus Gribi & $1889-1890$ & H2N2 olduğuna inanıldı (kuş kaynaklı) & 1 milyon \\
\hline İspanyol Gribi & $1918-1919$ & H1N1 virüsü / Domuzlar & 40-50 milyon \\
\hline Asya Grip & $1957-1958$ & H2N2 virüsü & 1,1 milyon \\
\hline Hong Kong Grip & $1968-1970$ & H3N2 virüsü & 1 milyon \\
\hline HIV / AIDS & 1981-Günümüz & Virüs / Şempanzeler & 25-35 milyon \\
\hline Domuz Gribi & 2009-2010 & H1N1 virüsü / Domuzlar & 200 bin \\
\hline SARS & $2002-2003$ & Coronavirus / Yarasalar, Civets & 770 \\
\hline Ebola & 2014-2016 & Ebolavirüs / Vahşi hayvanlar & $11 \mathrm{bin}$ \\
\hline MERS & 2015-Günümüz & Coronavirus / Yarasalar, Develer & 850 \\
\hline COVID-19 & 2019-Günümüz & Coronavirus - Bilinmiyor & 2,5-3 milyon \\
\hline
\end{tabular}

sebep olmuştur (Daszak vd., 2001). Tarım topluluklarına belirgin bir kayma olana kadar salgınların ölçeği ve yayılması dramatik bir şekilde artmamıştır. Ticaretin ulusal/uluslararası yayılımı, salgınları hızlandırarak insan ve hayvan etkileşimleri için yeni firsatlar yaratmıştır.
Sıtma, tüberküloz, cüzzam, veba, humma, grip, çiçek hastalığı ve diğerleri bu ilk yıllarda ortaya çıkmıștır.

İnsanlık son yıllarda, birçok bulaşıc1 hastalığ1 giderek artan bir ölçekte, sıklıkta ve daha yakından hissetmektedir: Ebola virüsü hastalı̆ğ, şiddetli akut 
Tablo 2. Dünyadaki ekonomik dalgalar

Döngü / dalga adı

Dönem (y1l)

Kitchin döngüsü (envanter)

Juglar döngüsü (sabit yatırım)

Kuznets döngüsü (altyapı yatırımı)

$15-25$

Kondratiev dalgası (teknolojik temel)

$45-60$

solunum sendromu (SARS), kuş ve pandemik influenza, Orta Doğu Solunum Sendromu (MERS) ve yakın zamanda ortaya çıkan koronavirüs hastalığı (COVID-19). Bu hastalıklar salginlara, can kaybı ve ticaret ve seyahatin aksaması gibi çok çeşitli sosyoekonomik sonuçlara da yol açmıştır. Yılda 4,5 milyar dolar olarak tahmin edilen hazırlığa yönelik finansman açı̆̆ı, yıllık 570 milyar dolar olan tahmini pandemik maliyetle karşılaştırıldığında oldukça azdır (WEF, 2019).

Ortaya çıkan bulaşıcı hastalıklar, Wuhan'da COVID-19'un ortaya çıması gibi kentsel ortamlarda ortaya çıkmakta veya 2003'te SARS salginları ve Amerika'da Zika virüs hastalığı gibi kentleşme nedeniyle hızla yayılmaktadır (Li vd., 2020). COVID-19 gibi diğer salginlar da, insanların gezegen üzerindeki etkisiyle tanımlanan jeolojik bir dönem olan Antroposen Çağı'nın bir yansımasıdır (McFarlane vd., 2013).

Kentler önemli seyahat ve ticaret merkezleridir; dolayısıyla bir salgın hayatın kaybedilmesinin ötesinde ciddi sosyo-ekonomik sonuçlara da yol açar. COVID19'un yayılmasından da görüldüğü gibi, hastalıklar artık hem ulusal hem de uluslararası olarak uçuşlarla büyük seyahat bağlantı modellerini takip ediyor (Bogoch vd., 2020). Insanlar daha büyük kentler kurdukça, daha egzotik ticaret yolları ve farklı insan, hayvan ve ekosistem popülasyonlariyla artan temas ile pandemilerin/ salgınların ortaya çıkması daha olası hale gelmiştir.

"Bugün, yeni ortaya çıkan bulaşıcı hastalıkların yaklaşık \%75’i çeşitli antropojenik, genetik, ekolojik, sosyoekonomik ve iklim faktörlerinden kaynaklanan zoonozlardır" (Gebreyes vd., 2017, s. 1).

Küreselleşmenin ve kentleşmenin etkisi ile zamanla meydana gelen önemli olan büyük pandemi ve salgınlardan bazıları aşağıdaki tablodaki gibidir (Tablo 1) (LePan, 2021).

Antroposen küreselleşmeden yerelleşmeye, kentleşmeden iklim değişikliğine birçok alanda etkisini gösterdiği gibi, salgın insidansının da artmasına neden olmuş/olmaktadır. Arazi kullanımındaki değişimler, yaban hayatının işgali, küreselleşme, nüfusun üssel artış1, tarımsal yoğunlaşma, aşırı ve çarpık kentleşme, pandemik patojenlerin kaynağ1 olan topluluklar/hayvanlar arasındaki patojen trafiğini gitgide arttırmaktadır (McMichael, 2001). Pandemi dünya çapında uluslararası

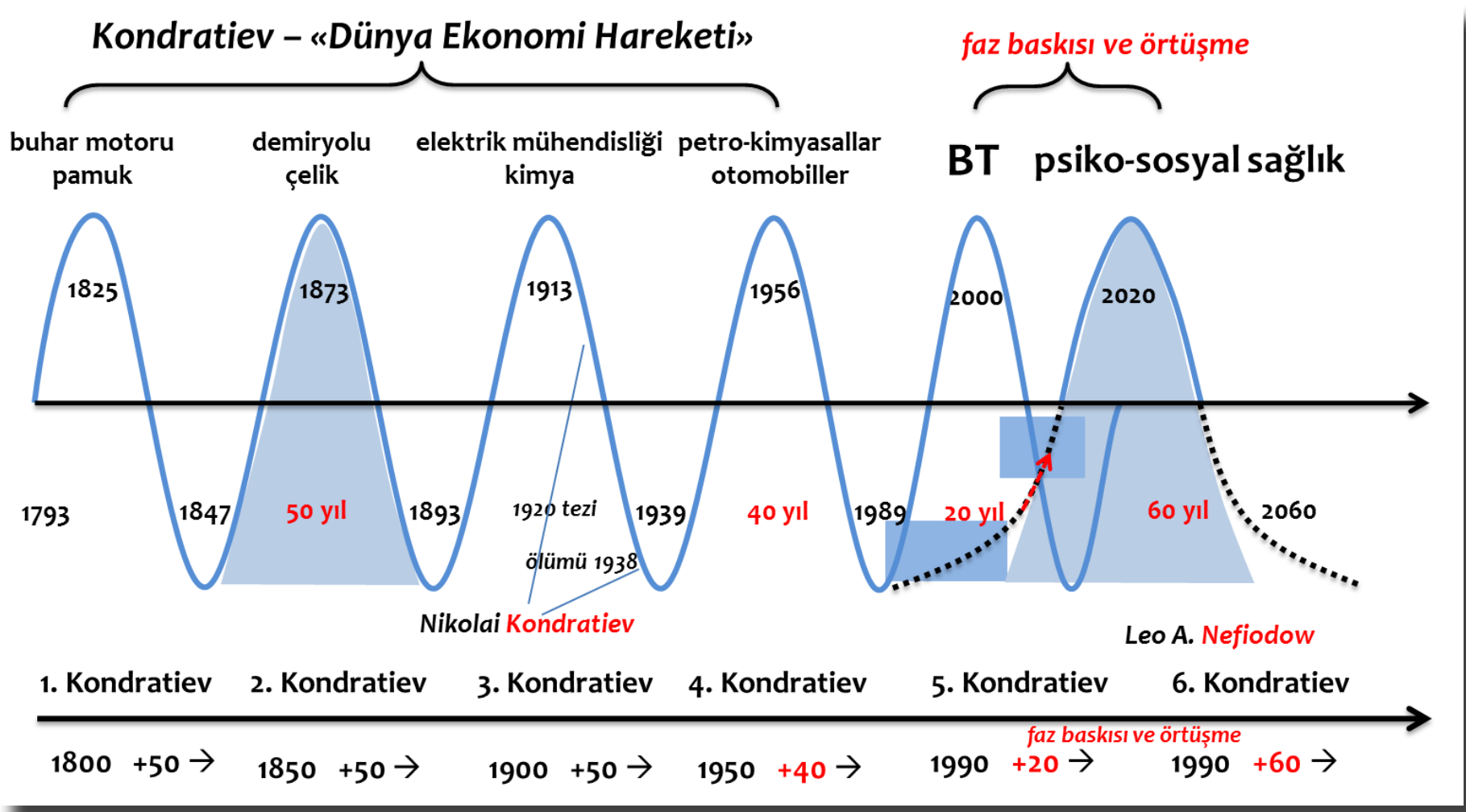

Şekil 1. Fą kayması ve örtüsmeyle BT ve sağlk.taki kazanımlarla ilişkili Kondratiev Dalgalar (Goldschmidt, 2004'ten uyarlanmıstır) 
sınırları aşan ve genellikle çok sayıda insanı etkileyen bir salgindir (Last, 2001).

Antroposen Çağ1 ile beraber "gezegensel sağlık sorunları" da ortaya çıkmaya başlamıştır. Rockefeller Vakfi-Lancet Komisyonu "Gezegensel Sağlik" raporunun tamaminda "Antroposen Çağı'nda insan sağlığının korunması"nı ele alarak bu konunun önemine değinmiştir (Whitmee vd., 2015).

Salgının ekonomik etkisi hiç de azımsanmayacak ölçeklerdedir; Leo A. Nefiodow'a (2014) göre, beşinci Kondratiev'in 2000-2003 küresel ekonomik krizi ile sona ermiş ve altıncı Kondratiev başlamıştır (Tablo 2). O'na göre, bu yeni uzun döngünün taşıyıcıs1, fiziksel, psikolojik, zihinsel, sosyal, ekolojik ve manevi yönleri de dahil olmak üzere bütünsel bir anlamda sağlık olacaktır; böylece altınc1 Kondratiev'in temel yenilikleri "psikososyal sağllk" ve "biyo-teknoloji" dir (Nefiodow ve Nefiodow, 2014).

Goldschmidt ve Hilbert (2009) ise Kondratiev'in BT ve sağlık döngülerinde (Şekil 1) bir faz kayması ve örtüşmesi olduğunu önerdi. Tarihsel büyüme evrelerinin kilit teknolojilerle kombinasyon halinde, genel olarak düzenli döngülerin varlığı anlamına gelmediğini savundu. Goldschmidt ve Hilbert (2009) farklı temel yeniliklerin ve ekonomik uyaranların, çoğunlukla uzunlukları değiştiği ve yararlarının bir piyasadaki tüm katılımcılar için geçerli olmadığı için birbirini dışlamadığı kanaatindedir.

\section{Antroposen Çağı'nda kentlerin pandemiyle imtihanı}

İnsanların içinde bulundukları ekosistemler üzerindeki etkileri bir dizi kronolojik geçişin ardından giderek daha da derinleşmiştir: (a) yerleşimlerin kurulması, tarımın yapılması ve hayvanlarının evcilleştirilmesi, avc1-toplayıcı kabilelerden metropollere geçiş; (b) merkantalizm, ticaret yoluyla küresel ve bölgesel bağlantı/etkileşim; (c) kıtalararası keşif, emperyalizm ve sanayileşme ve (d) küreselleşme, aşırı kentleşme ve iklim değişikliği (McMichael, 2004, s. 1049; Hassell vd., 2017, s. 55).

Antroposen Çağı'nın etkisi Sanayi Devrimi ile başlarken, bu etki 20. yüzyılda İkinci Dünya Savaşı'ndan sonra önemli ölçüde hissedilmeye başlanmış, "Büyük İvme" denilen bu dönemde artan kaynak tüketimi, atık üretimi, iklimsel ve diğer etkiler, atmosfer, okyanuslar, jeolojik müdahale (madencilik ve inşaat yoluyla toprak kaldırma gibi), bitki örtüsü vb. üzerinde yapılan değişiklikler Holosen sırasında insan türünün geliştirdiği, gezegen sınırlarını zorlayan yeni bir çağa itmiştir: Antroposen Çağ1 (Steffen vd., 2007). Antroposen için bir başlangıç tarihi kabul edilen Büyük İvme ile gelen demografik, çevresel, sosyal, teknolojik ve diğer değişiklikler, iklim değişikliği ile birleşik etkileri ortaya çıkararak bulaşıcı hastalık oluşumlarını da güçlendirmiştir. Örneğin, Himalaya buzulları yarım yüzyıl öncesine göre iki kat daha hızlı erimeye başlamış, 15.000 yaşındaki eriyen buzda 28 yeni viral yap1 bulunmuştur (Magnus-Johnston, 2020).

Antroposen'i dünya üzerindeki tek bir olayla ve insanın jeolojik kayıtlardaki izlerine dayanarak karakterize etmek doğru değildir. Fakat kentlerin Antroposen'in başlamasına neden olan felaket mekânları olduğu gerçeği de inkâr edilemez. Dünya nüfusu 1600 'de 600 milyon iken 2020 y1lında yaklaşık 8 milyar oldu. Sürekli üssel artan dünya nüfusu son zamanlarda 10-12 y1lda bir 1 milyar artmaya başladı ve bu da 2050 yılında nüfusun yaklaşı 10 milyar olması ile ilgili tahminlere sebep oldu. Bugün dünya nüfusunun yarısindan fazlası kentlerde yaşarken, 2050 yllına kadar dünya nüfusunun üçte ikisinin kentlerde yaşayacağı öngörüldü.

Antroposen Çağı'nın bir getirisi olan salgınların nerede meydana geldiğini ve bunların kentleşmenin getirdiği fiziksel, mekânsal, ekonomik, sosyal ve ekolojik değişikliklerle nasıl ilişkili olduğunu kavramak önemlidir. Herhangi bir zamanda, ortaya çıkan ölümcül ve bulaşıc1 bir patojen, küresel nüfusun bağlantıllllğı nedeniyle küresel olarak yayılma riski oluşturabilmektedir.

Kentler ile Antroposen arasında iki yönlü bir nedensel ilişki vardır: Antroposen'in hissedilmesinde kentsel süreçlerden kaynaklanan önemli katkılar ve kentlerin Antroposen'in getirdiği y1kıcı etkilere açı olan mekânlar olması (Trachtenberg, 2017). Bu yıkıc1 etkiler 21. yüzyılda sel, fırtına, kuraklaşma, aşırı hava olayları ve salg1n hastalıklar ile kendini yoğun bir şekilde kendini hissettirmektedir.

Artan nüfusu yerleştirmek için kentlerde hızlı arazi değişiklikleri meydana gelmeye başlayınca, küresel arazinin 3/4'ü ve denizlerin 2/3'ü önemli ölçüde değiştirildi ve insan için yapılan mekânlar yüzünden yaklaş1k 1 milyon hayvan ve bitki türü yok olma riskiyle karşı karşıya kaldı (IPBES, 2019). Kentleşme sera gazı emisyonlarını arttırmış, ortalama küresel sıcaklıkların sanayi öncesi zamanlara göre $1{ }^{\circ} \mathrm{C}$ artmasına neden olmuş ve iklim krizinin etkilerini giderek şiddetlendirmiştir. $\mathrm{Bu}$ küresel değişiklikler, sadece biyosfer için değil, sağlığımız da dâhil olmak üzere insanlı̆̆ın kendisi için belirsiz bir gelecek, diğer türler için de yok oluş anlamındadır. Ormansızlaşma ve doğal habitatların modifikasyonu da dâhil olmak üzere arazi kullanımı değişikliği, ortaya çıkan zoonozların (hayvanlardan insanlara bulaşabilen hastalıkların) yaklaşık yarısından sorumludur (Loh vd., 2015).

Zoonoz ile insan aktiviteleri, demografik büyüme ve kentleşme arasında doğrudan bir bağlantı vardır. Yaban hayat1, hayvancilık ve insanları birbirleriyle daha yakın temasa sokan arazi kullanımındaki değişiklikler, yeni bakteri ve virüs türleri de dâhil olmak üzere hastalıkların yayılmasını kolaylaştırmıştır. Eski ve yeni zoonozların gelişmesi için koşullar yaratan kentsel ortamlarda 
vahşi hayvanları satan pazarlarda birçok yeni salgının ve bulaşıcı hastalığın ortaya çıkması tesadüfi değildir (WWF, 2020, s. 3).

1940 'tan beri kentleşme, g1da üretimi ve tarımsal arazi kullanım değişikliği, zoonotik enfeksiyon hastalıklarının neredeyse \%50'sini oluşturmaktadır (Keesing vd., 2010, s. 651). Kent ile kır ve çevre arasındaki çizginin geçilmesi ile insanlar ile hayvanlarla olan temas artmıştır. Artan çevresel yıkım ve arazi kullanım değişikliği nedeniyle mevcut insan-ekosistem etkileşimi (doğal kaynakların kullanılması) ve iklim değişikliği gibi çevresel etkiler, habitat değişikliğine ve zoonotik hastalığın ortaya çıkmasını sağlayan temas oranlarında değişikliklere neden olmuştur/olmaktadır (Hassell vd., 2017, s. 56).

Son zamanlarda ortaya çıkan salginların yaratıcıları kentlerdir ve bundan en çok etkilenen de kentli insanlardır. Hızlı kentleşme, doğal yaşam alanlarına girmeye ve vahşi yaşam ve zoonozlarla daha yakın karşılaşmalara yol açmakta, gıda pazarlarındaki hayvanlara artan yakınlık da zoonotik enfeksiyonlar için firsatlar sağlamaktadır. Hem SARS hem de COVID19'un gida pazarlarından kaynaklanmış olabileceğine dair tezler vardır. Kısaca ortaya çıkan bulaşıcı hastalıkların nasıl ve nerede yaşadığımızla ilgisi vardır. Devam eden koronavirüs, kentsel gelişim ile yeni veya yeniden ortaya çıkan bulaşıcı hastalıklar arasındaki yakın ilişkilere bir örnektir (Keil vd., 2020).

Antroposen Çağı'nı tanımlarken, küresel anlık çevresel geçişlere odaklanmak yerine bu dönüştürücü sosyal-çevresel-teknolojik-kentsel değişiklikleri incelemeyi de dikkate almak gerekmektedir. Jeolojik Zaman Çizelgesi'nde tarihin seyrini değiştiren stratigrafik "Altın Noktalar" vardır. Bu noktalar ve geçişler Antroposen'in bir günde yapılmadığını, aynı şekilde de yaratılmadığını, yani dünyadaki insan değişikliklerinin maddi kayıtlarının kalın, derin ve heterojen olduğunu belirtmektedir (Ellis vd., 2016, s. 193).

Tarihsel zaman çizelgesinde kültürel değişiklikler de bilgi çağı, fosil yakıtlar, yoğun ticaret ağları, kentler, tarım, insan kültürleri çevresel etkilere sebep olmuştur. Bu çevresel etkiler sera gazı emisyonlarının hızla artmasını, arazi kullanımı ile ormansızlaşmayı, pandemilere/ salginlara neden olan tür girişleri ile etkileşimi, kitlesel yok oluşlarla nesillerin tükenmesini arttırmıştır. Bütün bunlar gezegenimizi önemli ölçüde değiştirdiğimizin işaretleridir. Ve bu değişiklikler yeni bir resmi jeolojik çağ olan Antroposen'in kanıtlarını göstermektedir.

Antroposen Çağı'ndakültürelveçevreseldeğişiklikler jeolojik zamanı değiştiren altın noktalara sebep olurken bu değişiklikler aynı zamanda pandemilerin/salgınların da ortaya çıkmasina neden olmuştur. Antroposen Çağı'nın göstergeleri arttıkça salgin hastalıklar da artmıştır, bu başlangıcın ve artışın kentlerin doğuşu ile de ilişkili olduğu açıkça görülmektedir (Şekil 2).

\section{Sonuç yerine}

Kentleşme dünyada hala devam eden bir süreç, ancak sürecin hızı evrensel değildir. Geleneksel olarak gelişmiş ülkeler zaten kentleşmiştir ve gelişmekte olan ülkelerde de hızlı bir yükseliş gerçekleşmektedir.

Dünya nüfusu katlanarak büyümeye devam etmekte ve daha fazla insan kentlerde ve mega-kentlerde yaşamaya yönelmektedir. Ancak kentsel ortamlar her zaman potansiyel risk ve tehditlerle birlikte hastalıklarla da bağlantıllıdır. Bulaşıcı hastalıkların küresel sağlık üzerindeki büyük etkisi ve kentleşme bu hastalıkların özelliklerini de değiştirmektedir. Kentsel ortamdaki farklı risk faktörleri, örneğin, böcek ve kemirgen vektör hastalıkları ve ortam kaynaklı jeohelmintiyazların/ parazitlerin çoğalması olabilir. Bu, kentsel altyapıdaki yetersiz su kaynaklarının yanı sıra sağlık ve atık yönetimine de bağl1 bir durumdur.

Binaların yakıt ve havalandırma sistemlerinden yoksun olması solunum yolu enfeksiyonlarını tetiklerken, kirlenmiş su, mikrobiyal toksinler ve zoonozlar nedeniyle kötü gıda, yanlış depolama ve satış hastalıkları yayabilmektedir. Kentlerin yoğunluğu ve kentsel alanlardaki insanlar arasındaki yakın temas, COVID-19 gibi bulaşıcı hastalıkların hızla yayılması için potansiyel sıcak noktalardır. Kentlerin sürekli değișen ortamı, bulaşıcı hastalıkların hem ortaya çıkmasını hem de hızla yayılmasını sağlar. Kırsal ortamlardan kentsel çevrelere uyum sağlayan patojenler de daha hızlı yayılabilir ve sağlık hizmetlerine daha büyük bir yük olușturabilir.

Kentlerin gelişmiş sağlik sistemlerine sahip ve erişebilir olması avantajını gösterirken, bireysel mesafenin korunamadığı, salginların hızla yayıldığ1 ortamlar olması da dezavantajını oluşturur. Kentler ayrica pandemilere hazırlık, hafifletme ve adaptasyonda merkezi bir rol oynamaktadır. Ekosistemlerimizin nasıl ișlediğini ve özellikle bizi hastalıkların yayılmasından korumadaki rollerini daha iyi anlamamı gerekmektedir. Zoonotik hastalık riskini engellemede bölgesel/kentsel stratejik mekânsal planlama önemli bir husus olmalıdır.

Kentsel ortamların özellikleri ile ilişkili salgı̣n hazırlıkları için zorluklar ve firsatlarda "Yönetilecek daha büyük bir nüfus; sıkışık alanlarda insanlar arasında yayılan hastalık kolaylığı; temas izlemedeki zorluklar, özellikle kamusal alanlarda nedensel temas; salgin önleme ve kontrol çabalarını engelleyebilecek kötü barınma ortamlarına yol açan eşitsizlikler; Gıda pazarları yoluyla veya daha önce el değmemiş ekosistemlere genişleme nedeniyle yaban hayatıyla daha yakın karşılaşmalar" yer almaktadır (Lee vd., 2020, s. 1).

Quammen (2012) “uzmanlar, bir sonraki ölümcül insan salgınının neredeyse kesinlikle vahşi yaşamdan insanlara geçen bir virüs olacağına inanıyorlar" derken bugün, 2020 yılında, COVID-19 salgınını kastetmişti herhalde. Yine, Nobel Ödüllü Moleküler Biyolog J. 


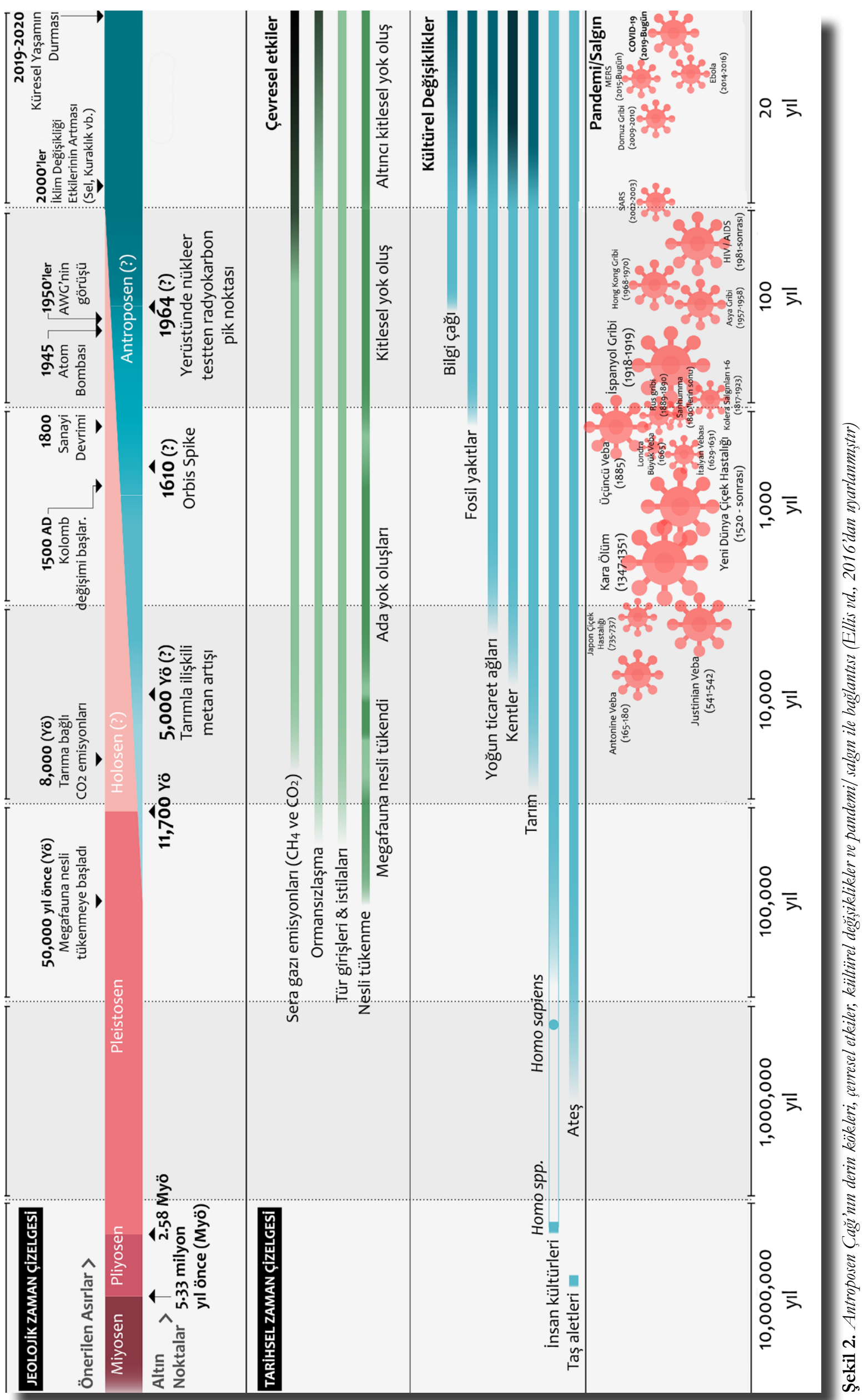


Lederberg ve ekibinin (1992), virüslerin “insanın bu gezegendeki devam eden egemenliğine karşı en büyük tehdidi oluşturduğu" konusundaki uyarısı tesadüfi değildi. Bu noktada, COVID-19 salginı ve diğer pandemilerin doğrudan ya da dolaylı olarak bir insan yaratımı olduğunu anlamak önemlidir.

$\mathrm{Bu}$ bulaşıcı virüslerin ortaya çıkışını kentin çevreyle olan ilişkisi ve ekolojik olarak da yorumlamak gerekir: Yangınlar, sel, kuraklık nedeniyle belirli türlerin (virüs rezervuarları) doğal yaşam alanlarının ve ekosistemlerinin yok edilmesi / dönüştürülmesi, iklim değişikliği veya bazı türlerin yerinden edilmesinin ve insanlarla tehlikeli yakınlaşması (örneğin Afrika'da HIV ve Ebola) ormansızlaşma, kaçak avlanma veya insan / vahşi yaşam alanlarının insan sağlığı için riskli olmasına neden olan hayvan biyotoplarını çevreleyen yerleşmelerin orantısız bir şekilde genişletilmesi ve plansız, çarpık, kontrolsüz kentleşme nedeniyle. Bu bakımdan, insanlar ve fauna arasında bir ayrım yapmak, hayvan ve bitki biyotoplarına sayg1 duymak ve ekosistemlerini korumak bir zorunluluktur.

Birçok bilim insanının iddia ettiği gibi, Antroposen hipotezi, çevre teorisi ve praksisini anlatan bazı analitik kategorilerin radikal bir şekilde yeniden düşünülmesini gerektirir. Birlikte ele alındığında, Antroposen ve kentleşmeyle ilgili sorular, doğa/toplum ve kırsal/ kentsel ikilisi arasındaki bağlantıları vurgulamaktadır ve aynı zamanda onları sınırlamaya itmektedir.

Çalıların etrafindan dolaşmaya gerek yok, gerçek şu ki, insanlar, gezegene ya da Gaia'ya bela olmanın eșiğinde. Acımasız "yaratıcı y1kım" ve karbon temelli kapitalizmin "hafriyatçllı (extractivism)" koşulları altında, insanlar diğer tüm türlere ve ekosisteme karş1 maalesef bir belaya dönüşüyor. Ekosistemin sınırlarını epeyce zorladığ1 için, batan gemiden ilk kaçanlar da insanlar oluyor.

Yeni anormal, kaçınılmaz veya "teknolojik olarak yönetilebilir" olarak kabul edilen bu gezegen eğer insan egemenliğinin bir sonucuysa, o zaman Antroposen ile özdeşleşmeyi de kabul etmek gerekecek. Demokrasi, sürdürülebilirlik, sürdürülebilir kalkınma ve uyum kapasitesi gibi kavramlar etrafında yeni ve yaşanabilir bir toplum kurmaya çalışmış olsak da; tüm bu terimler, normalleştirildikleri, her zamanki gibi ateşine odun taşıdıkları Antroposene dâhil edildikleri ve yerleştirilmeye çalıştıkları için bu kuvvetler tarafindan -artık- bozuldu.

Son olarak Rull'un (2017, s. 1056-1059) sözleri ile bitirecek olursak, "Antroposen'in şu andaki tanımı geleceğe yapılan bir bahistir ve dolayısıyla anlamı ve nihaî biçimselleştirilmesi, insan ilişkilerinin gelecekteki gelişimine bağlıdır... Bir tür olarak yok olmamı 'Antroposen'in ya da 'Antropozoik'in sonunu belirleyecektir".

\section{Kaynakça}

Akbari, H., Menon, S., ve Rosenfeld, A. (2009). Global cooling: increasing world-wide urban albedos to offset CO2. Climatic Change, (94), 275-286. https://doi.org/10.1007/s10584-0082515-9

Aykanat, F. (2017). Antroposen Çağının öykü anlatıcıları: sanat ve edebiyat. Sarki Edebiyat ve Sanat Dergisi, 1(2), 1-17.

Bogoch, I., Watts, A., Thomas-Bachli, A., Huber, C., Kraemer, M.U.G., ve Khan, K. (2020). Potential for global spread of a novel coronavirus from China. Journal of Travel Medicine, 27(2), 1-3. https://doi.org/10.1093/itm/taaa011

Certini, G., ve Scalenghe, R. (2011). Anthropogenic soils and the golden spikes for the Anthropocene. The Holocene, 21(8), 1269-1274. https://doi.org/10.1177/0959683611408454

Chakrabarty, D. (2009). The climate of history: four theses. Critical Inquiry, 35(2), 197-222. https://doi.org/10.1086/596640

Cicolella, A. (2013). Toxique planète: Le scandale invisible des maladies cbroniques. Éditions du Seuil.

Crist, E. (2013). On the poverty of our nomenclature. Environmental Humanities, 3(1), 129-147. https://doi.org/10.1215/22011919$\underline{3611266}$

Crutzen, P. J. (2002). Geology of mankind. Nature, (415), 23. https://doi.org/10.1038/415023a

Crutzen, P. J., ve Steffen, W. (2003). How long have we been in the Anthropocene Era? An editorial comment. Climatic Change, 61(3), 251-257. https://doi.org/10.1023/ B:CLIM.0000004708.74871.62

Daszak, P., Cunningham, A., ve Hyatt, A. (2001). Anthropogenic environmental change and the emergence of infectious diseases in wildlife. Acta Tropica, 78(2), 103-116. https://doi. org/10.1016/S0001-706X(00)00179-0

Demos, T. J. (2017). Aganist the Anthropocene: visial culture and environment today. Sternberg Press.

Ellis, E., Maslin, M., Boivin, N., ve Bauer, A. (2016). Involve social scientists in defining the Anthropocene. Nature, (540), 192193. https://doi.org/10.1038/540192a

Foucault, M. (1977). Discipline \& Punish: the birth of the prison. Vintage Books.

Gebreyes, W. A., Dupouy-Camet, J., Newport, M. J., Oliveira, C. J., Schlesinger, L. S., Saif, Y. M., Kariuki, S., Saif, L. J., Saville, W., Wittum, T., Hoet, A., Quessy, S., Kazwala, R., Tekola, B., Shyrock, T., Bisesi, M., Patchanee, P., Boonmar, S., ve King. L. J. (2014). The global one health paradigm: challenges and opportunities for tackling infectious diseases at the human, animal, and environment interface in low-resource settings. PLoS Neglected Tropical Diseases, 8(11), 1-6. https://doi. org/10.1371/journal.pntd.0003257

Goldschmidt, A. J. W., ve Hilbert, J. (2009). Health economy in Germany - economical field of the future (Gesundheitswirtschaft in DeutschlandDie Zukunftsbranche). Wikom Publishing House.

Goldschmidt, J. W. (2004). Kondratiev waves associated with gains in 1t and health with phase shift and overlap. https://www. uni-trier.de $/$ index.php?id $=28954$

Hamilton, C. (2014). Can humans survive the Anthropocene? 
https://clivehamilton.com/can-humans-survive-theanthropocene/

Hassell, J. M., Begon, M., Ward, M.J., Fevre, E.M. (2017). Urbanization and disease emergence: dynamics at the wildlifelivestock-human interface. Trends in Ecology \& Evolution, 32(1), 55-67. https://doi.org/10.1016/i.tree.2016.09.012

IPBES (2019). Summary for policymakers of the global assessment report on biodiversity and ecosystem services of the Intergovernmental Science-Policy Platform on Biodiversity and Ecosystem Services. . S. Díaz, J. Settele, E. S. Brondízio E.S., H. T. Ngo, M. Guèze, J. Agard, A. Arneth, P. Balvanera, K. A. Brauman, S. H. M. Butchart, K. M. A. Chan, L. A. Garibaldi, K. Ichii, J. Liu, S. M. Subramanian, G. F. Midgley, P. Miloslavich, Z. Molnár, D. Obura, A. Pfaff, S. Polasky, A. Purvis, J. Razzaque, B. Reyers, R. Roy Chowdhury, Y. J. Shin, I. J. Visseren-Hamakers, K. J. Willis, ve C. N. Zayas (ed.). IPBES secretariat. Bonn. https://doi.org/10.5281/zenodo.3553579

Keesing, F., Belden, L. K., Daszak, P., Dobson, A., Harvell, C. D., Holt, R. D., Hudson, P., Jolles, A., Jones, K. E., Mitchell, C. E., Myers, S. S., Bogich, T., ve Ostfeld, R. S. (2010). Impacts of biodiversity on the emergence and transmission of infectious diseases. Nature, (468), 647-652. https://doi.org/10.1038/ nature 09575

Keil, R., Connolly, C., ve Ali, S. H. (2020). Outbreaks like coronavirus start in and spread from the edges of cities. the conversation. https://theconversation.com/outbreaks-like-coronavirusstart-in-and-spread-from-the-edges-of-cities-130666

Last, J. M. (2001). A dictionary of epidemiology (4 $\left.4^{\text {th }} \mathrm{ed}\right)$. Oxford University Press.

Lederberg, J., Shope, R. E., Oaks, S. C. (1992). Emerging infections: microbial threats to health in the United States. National Academy Press.

Lee, V. J., Ho, M., Kai, C.W., Aguilera, X., Heymann, D., ve Wilder-Smith, A. (2020). Epidemic preparedness in urban settings: new challenges and opportunities. The Lancet Infect Diseases, 20(5), 527-529. https://doi.org/10.1016/S14733099(20)30249-8

Lepan, N. (2021). Visualizing the history of pandemics. https:// www.visualcapitalist.com/history-of-pandemics-deadliest/ (En son 8 Mart 2021'de erişilmiştir)

Li, Q., Guan, X., Wu, P., Wang, X., Zhou, L., Tong, Y., Ren, R., Leung, K. S. M., Lau, E. H. Y., Wong, J. Y., Xing, X., Xiang, N., Wu, Y., Li, C., Chen, Q., Li, D., Liu, T., Zhano, J., Liu, M., Tu, W., ... Feng, Z. (2020). Early transmission dynamics in Wuhan, China, of novel coronavirus-1nfected pneumonia. The New England Journal of Medicine, (382), 1199-1207. https://doi. org/10.1056/NEJMoa2001316

Loh, E., Zambrana-Torrelio, C., Olival K.J., Bogich, T.L., Johnson, C.K., Mazet, J. A. K., Karesh, W., ve Daszak, P. (2015). Targeting transmission pathways for emerging zoonotic disease surveillance and control. Vector-Borne and Zoonotic Diseases, 15(7), 432-43. https://doi.org/10.1089/ vbz.2013.1563

Magnus-Johnston, J. (2020). Outbreaks in the Anthropocene: growth ain't the cure. https://www.resilience.org/ stories/2020-03-12/
McFarlane, R. A., Sleigh, A. C., ve McMichael, A. J. (2013). Landuse change and emerging infectious disease on an island continent. International Journal of Environmental Research and Public Health, 10(7), 2699-2719. https://doi.org/10.3390/ ijerph10072699

McMichael, A. J. (2001). Human culture, ecological change, and infectious disease. Ecosystem Health, 7(2), 107-115. https://doi. org/10.1046/j.1526-0992.2001.007002107.x

McMichael, A. J. (2004). Environmental and social influences on emerging infectious diseases: past, present and future. Philosophical Transactions of the Royal Society B, Biological Sciences, 359(1447), 1049-1058. https://doi.org/10.1098/ rstb.2004.1480

Nefiodow, L.A. (2014). Health: The economic growth engine of the 21 st century. ICU Management \& Practice, 14(4), 1-6.

Nefiodow, L.A., Nefiodow, S. (2014). The sixth kondratieff, a new long wave in the global economy. Createspace Independent Pub.

Hine, R. (Ed.) (2019). A dictionary of biology (8th ed.). Oxford University Press.

Parnell, S. (2016). Defining a global urban development agenda. World Development, (78), 529-540. https://doi.org/10.1016/j. worlddev.2015.10.028

Peters, K. E. (2012). The whole story of climate: what science reveals about the nature of endless change. Prometheus Books.

Pike, J., Bogich, T., Elwood, S., Finnoff, D. C., ve Daszak, P. (2014). Economic optimization of a global strategy to address the pandemic threat. Proceedings of the National Academy of Sciences, 111(52), 18519-18523. https://doi.org/10.1073/ pnas. 1412661112

Quammen, D. (4 Ekim 2012). The next pandemic: Why it will come from wildlife. Yale Environment 360. https://e360.yale. edu/features/quammen the next pandemic will come from wildlife

Rafferty, J. P. (2020). Anthropocene Epoch. https://www. britannica.com/science/Anthropocene-Epoch

Rull, V. (2017). The "Anthropocene": Neglects, misconceptions, and possible futures. EMBO Reports, 18(7), 1056-1060. https://doi.org/10.15252/embr.201744231

Seto, K.C., Sánchez-Rodríguez, R., ve Fragkias, M. (2010). The new geography of contemporary urbanization and the environment. Annual Review of Environment and Resources, (35), 167-194. https://doi.org/10.1146/annurevenviron-100809-125336

Steffen, W., Crutzen, P.J., ve Mcneill, J. R. (2007). The Anthropocene: are humans now overwhelming the great forces of Nature? AMBIO: A Journal of the Human Environment, 36(8), 614-621. https://doi.org/10.1579/0044-7447(2007)36[614:TAAHNO 12.0. $\mathrm{CO} ; 2$

The Economist (2011). Welcome to the Anthropocene. https:// www.economist.com/leaders/2011/05/26/welcome-to-theanthropocene

Trachtenberg, Z. (6 Eylül 2017). The urban Anthropocene. Inhabiting the Anthropocene. https://inhabitingtheanthropocene. com/2017/09/06/the-urban-anthropocene/ 
WEF (World Economic Forum) (2019). Outbreak readiness and business impact: Protecting lives and livelihoods across the global economy. World Economic Forum. http://www3. weforum.org/docs/WEF\%20HGHI Outbreak Readiness Business Impact.pdf

Whitmee, S., Haines, A., Beyrer, C., Boltz, F., Capon, A. G., De Souza Dias, B. F., ... (2015). Safeguarding human health in the Anthropocene epoch: report of The Rockefeller Foundation-Lancet Commission on planetary health. The Lancet, 386(10007), 1973-2028. https://doi.org/10.1016/ $\underline{\mathrm{S} 0140-6736(15) 60901-1}$

WWF (2020). The loss of nature and rise of pandemics: Protecting human and planetary health. WWF Italy. https://wwfint. awsassets.panda.org/downloads/the loss of nature and rise of pandemics protecting human and planetary health.pdf

Zalasiewicz, J., Waters, C. N., Summerhayes, C. P., Wolfe, A. P., Barnosky, A. D., Cearreta, A., Crutzen, P., Ellis, E., Fairchild, I. J., Gałuszka, A., Haff, P., Hajdas, I., Head, M. J., Ivar do Sul, J. A., Jeandel, C., Leinfelder, R., McNeil, J. R., Neal, C., Odada, E., Oreskes, N., ... Williams, M. (2017). The working group on the Anthropocene: summary of evidence and interim recommendations). Anthropocene, (19), 55-60. https://doi. org/10.1016/j.ancene.2017.09.001

Zalasiewicz, J., Williams, M., Smith, A., Barry, T. L., Coe, A. L., Bown, P. R., Brenchley, P., Cantrill, D., Gale, A., Gibbard, P., Gregory, F. J., Hounslow, M. W., Kerr, A. C., Pearson, P., Knowx, R., Powell, J., Waters, C., Marshall, J., Oates, M., Rawson, P., ve Stone, P. (2008). Are we now living in the Anthropocene? GSA Today, 18(2), 4-8. http://doi. org/10.1130/GSAT01802A.1

\section{(c) (1) () \\ BY NC}

2021. Telif haklar1 yazar(lar)a aittir.

Bu makale Creative Commons Atıf-GayriTicari 4.0 Uluslararası (CC BY-NC 4.0) lisansının hüküm ve şartları altında yayımlanan açık erişimli bir makaledir. 